(C) 2021, The Authors. Published by Elsevier Inc. and Fass Inc. on behalf of the American Dairy Science Association ${ }^{\circledR}$. This is an open access article under the CC BY-NC-ND license (http://creativecommons.org/licenses/by-nc-nd/4.0/).

\title{
Short communication: Heterosis and breed effects for milk production and udder health traits in crosses between Danish Holstein, Danish Red, and Danish Jersey
}

\author{
M. Kargo, ${ }^{1,2 *} \oplus$ J. B. Clasen, ${ }^{1,2} \oplus$ H. M. Nielsen, ${ }^{1} \odot$ K. Byskov, ${ }^{2} \oplus$ and E. Norberg ${ }^{1} \oplus$ \\ ${ }^{1}$ Center for Quantitative Genetics and Genomics, Faculty of Science and Technology, Aarhus University, DK-8830 Tjele, Denmark \\ ${ }^{2}$ SEGES, Agro Food Park 15, 8200 Aarhus N, Denmark
}

\begin{abstract}
During the last decade, the use of systematic crossbreeding in dairy cattle herds has increased in several countries of the world. The aim of this study was to estimate the effect of breed proportion and heterosis on milk production traits and udder health traits in dairy cattle. The study was based on records on milk yield (MY), protein yield (PY), fat yield (FY), somatic cell score (SCS), and mastitis (MAST) from 73,695 first-lactation dairy cows in 130 Danish herds applying systematic crossbreeding programs. Around $45 \%$ of the cows were crosses between Danish Holstein (DH), Danish Red (DR), or Danish Jersey (DJ), and the remaining were purebred DH, DR, or DJ. The statistical model included the fixed effects of herd-year, calving month, and calving age and an effect representing the lactation status of the cow. In addition, the model included a regression on calving interval from first to second lactation, a regression on the proportion of DH, DR, and DJ genes, and a regression on the degree of heterozygosity between DH and DR, DH and DJ, and DR and DJ. Random effects were the genetic effect of the cow and a residual. The effect of breed proportions was estimated relatively to DH. For MY, a pure DR yielded $461 \mathrm{~kg}$ milk less than $\mathrm{DH}$, whereas a pure DJ yielded $2,259 \mathrm{~kg}$ milk less than a pure DH. Compared with DH, PY was $41.7 \mathrm{~kg}$ less for DJ, whereas PY for DR was $4.0 \mathrm{~kg}$ less than for DH. For FY, a DR yielded $10.6 \mathrm{~kg}$ less than $\mathrm{DH}$, whereas there was no significant effect of breed proportion between DJ and DH. A DR cow had lower SCS (0.13) than DH, whereas DJ had higher SCS (0.14) than DH. There was no significant effect of breed proportion on MAST between the 3 breeds. Heterosis was significant in all combinations of breeds for MY, FY,
\end{abstract}

Received November 7, 2019.

Accepted August 17, 2020.

*Corresponding author: morten.kargo@qgg.au.dk and PY. Heterosis for crosses between DH and DR was $257 \mathrm{~kg}(3.2 \%), 11.9 \mathrm{~kg}(3.2 \%)$, and $8.9 \mathrm{~kg}(3.2 \%)$ for MY, PY, and FY, respectively. Corresponding figures for crosses between DH and DJ were $314 \mathrm{~kg}$ (4.4\%), $14.3 \mathrm{~kg}(4.4 \%)$, and $10.4 \mathrm{~kg}(4.0 \%)$, whereas heterosis between DR and DJ was $462 \mathrm{~kg}(6.7 \%), 19.6 \mathrm{~kg}(6.7 \%)$, and $13.9 \mathrm{~kg}(5.4 \%)$ for MY, PY, and FY, respectively. Heterosis was only significant for SCS in the crosses between DH and DR. Heterosis effects for MAST were nonsignificant for all the crosses. The results obtained in this study demonstrate that in first lactation cows, there is a positive effect of heterosis on milk production traits, but limited effect on udder health traits.

Key words: heterosis, milk production, udder health, dairy cow

\section{Short Communication}

Crossing of lines or breeds is systematically used in breeding programs for pigs and poultry, and it has also proved to be beneficial in dairy cattle breeding (LopezVillalobos et al., 2000; Sørensen et al., 2008). Crossbred cows have approximately same level or higher milk yield, better reproduction, and improved survival compared with Holstein (Heins et al., 2006; Dezetter et al., 2015; Clasen et al., 2019; Clasen et al., 2020). Therefore, the use of systematic crossbreeding has increased during the last decade in dairy cattle herds in many countries. When applying crossbreeding, differences in additive genetic level between breeds are used in addition to the heterosis expressed by the crossbred animals. Crossbred animals are supposed to be more economically efficient and more robust compared with the parental breeds (Mäki-Tanila, 2007; Heins et al., 2012; Clasen et al., 2020). Profit is mainly improved if the breeds used for crossbreeding have approximately the same genetic level for total merit (Sørensen et al., 2008). On top of that, heterosis is added as a bonus. For milk production traits, heterosis effects range between 1.5 to $8.4 \%$ (Sørensen et al., 2008; Dechow et al., 2007; Lembeye et 
Table 1. Number of crossbred cows, purebred Danish Holstein (DH), Danish Red (DR), and Danish Jersey (DJ), and breed proportion in crossbred cows

\begin{tabular}{|c|c|c|c|c|c|c|c|c|c|}
\hline Item & $\begin{array}{c}\text { No. of } \\
\text { cows }\end{array}$ & \multicolumn{3}{|c|}{ Breed proportion } & \multicolumn{5}{|c|}{ Trait $^{1}$} \\
\hline $\mathrm{DH}$ & 34,434 & 1.0 & - & - & 282.3 & 8,460 & 338.0 & 11.51 & 0.103 \\
\hline DR & 3,315 & - & 1.0 & - & 272.0 & 7,809 & 329.0 & 11.49 & 0.102 \\
\hline DJ & 2,981 & - & - & 1.0 & 240.0 & 5,915 & 342.5 & 11.77 & 0.126 \\
\hline
\end{tabular}

${ }^{1} \mathrm{PY}=$ mean protein yield; $\mathrm{MY}=$ mean milk yield; $\mathrm{FY}=$ mean fat yield; MAST = incidence of mastitis; PY, MY, and FY measured in kilograms; SCS measured in somatic cells per milliliter.

al., 2016). Heterosis is expected to be larger for functional traits than for production traits (Sørensen et al., 2008). There are only a few studies reporting heterosis estimates on udder health traits, and the results are contradictory (VanRaden and Sanders, 2003; Dechow et al., 2007; Sørensen et al., 2008). However, these studies were mainly based on a limited number of animals, and it was difficult to separate breed and heterosis effects, as the phenotype of interest was not recorded on purebred cows in the herds with crossbred cows.

In this study, records on both purebred and crossbred animals from herds applying systematic crossbreeding programs were used to estimate breed effects and heterosis. The systems used were rotational crossbreeding and the crossbreeding system Combi-Cross as described in Kargo et al. (2014). The herds were chosen to avoid bias from only low-ranking cows being used for crossbreeding. All types of crossbred animals from these herds, such as first-generation $\left(\mathbf{F}_{1}\right)$ crossbred, backcrosses, and animals from rotational crossbreeding systems, were included in the analyses. Data were from first-lactation cows in Denmark that calved between October 24, 1998, and September 28, 2016. All records were gathered from the input files to be used in the Nordic breeding value estimation (NAV, 2020) and followed the editing rules used for data to be included in the Nordic breeding value estimation. Three milk production traits were included in this study: 305-d milk yield (MY), 305-d protein yield (PY), and 305-d milk fat yield (FY), all measured in kilograms. Records on MY ( $\mathrm{n}=72,728)$, PY $(\mathrm{n}=72,728)$, and FY $(\mathrm{n}=72,728)$ were raw 305 -d yield in first lactation measured in kilograms. Lactations were extended using similar procedures as described in Wiggans and Van Vleck (1979). In addition, 2 udder health traits were included: SCC measured in somatic cells per milliliter and incidence of mastitis (MAST). Somatic cells per milliliter $(\mathrm{n}=73,459)$ were recorded every month during the lactation period and transformed to SCS using natural logarithm transformation. An average of the transformed observations between 4 and 175 DIM were used as lactation SCS. Records on MAST $(\mathrm{n}=73,678)$ was a binary score with the score of 1 if the cow was treated for mastitis during the period of $15 \mathrm{~d}$ before first calving to $50 \mathrm{~d}$ after first calving, and a 0 if the cow did not receive any mastitis treatments.

Data were from 119 herds practicing crossbreeding and an additional 11 mixed-breed herds, which had both Danish Jersey (DJ) and Danish Holstein (DH). These mixed-breed herds were included to estimate reliable breed effects of DJ due to a low number of purebred DJ in the crossbred herds. The percentage of crossbred cows was 44.7, and the crosses were between DH and Danish Red (DR), DH and DJ, and DR and DJ. The remaining cows were purebred DH, DR, or DJ (Table 1). Only cows with more than 45 DIM and a calving age between 18 and 40 mo were included. For cows without information on date for second calving, we inserted the mean calving interval. Cows with an unknown breed proportion of more than $12.5 \%$ were excluded from the analysis. For cows with less than $12.5 \%$ unknown breed, the unknown proportion was substituted with the breed representing the largest proportion (DH, DR, or DJ). The breeds DH, DR, and DJ contain more lines. For example, DH mainly consists of Holstein Friesian, but it also contains a small proportion of the original Danish Black and White breed. Danish Red contains a small proportion of the original DR breed, whereas the remaining part is a mixture of Swedish Red, Norwegian Red, Canadian Ayrshire, Finnish Ayrshire, American Brown Swiss, and Red Holstein Friesian (SEGES, 2019). Because Red Holstein Friesian is genetically closer related to DH than DR, the breed was included in DH instead of DR within the crossbred cows. The breed DJ is a mixture of Danish, New Zealand, and American Jersey.

Breed proportions and heterosis were derived from an animal model using the AI-REML algorithm included in the DMU package (Madsen and Jensen, 2013). The convergence criterion used was a change in the norm of the update. The pedigree was traced back 4 generations in the Danish Cattle Database (Bundgaard and $\mathrm{H} \varnothing \mathrm{j}$, 2000), and the pedigree file included 262,027 animals.

The statistical model used to analyze the data was: 
Table 2. Effect of breed proportion for Danish Red (DR) and Danish Jersey (DJ) on protein (PY), milk (MY), fat (FY), SCS, and incidence of mastitis (MAST) relative to Danish Holstein ${ }^{1}$

\begin{tabular}{|c|c|c|c|c|c|}
\hline Item & PY & MY & FY & SCS & MAST \\
\hline $\mathrm{DR}$ & $-4.0(3.7)^{*}$ & $-461(130)^{*}$ & $-10.2(4.8)^{*}$ & $-0.13(0.07)$ & $-0.0004(0.02)$ \\
\hline DJ & $-41.7(4.9)^{*}$ & $-2,259(173)^{*}$ & $-1.8(6.3)$ & $0.14(0.1)$ & $0.017(0.02)$ \\
\hline
\end{tabular}

$$
\begin{gathered}
Y_{i j k l m}=H_{i}+C_{j}+M_{k}+G_{l}+b \times C I+b_{1} \times p_{D H}+b_{2} \\
\times p_{D R}+b_{3} \times p_{D J}+b_{1 \backslash 2} \times h e t_{D H \mid D R}+b_{1 \backslash 3} \times \text { het }_{D H \mid D J} \\
+b_{2 \backslash 3} \times h e t_{D R \mid D J}+a_{m}+e_{i j k l m},
\end{gathered}
$$

where $Y_{i j k l m}=\mathrm{MY}$, PY, FY, SCS, or MAST for cow $m ; H_{i}=$ fixed effect of herd-year $i(i=1, \ldots, 905) ; C_{j}$ $=$ fixed effect of calving month $j(j=1, \ldots, 12) ; M_{k}=$ fixed effect of calving age in month $k(k=18, \ldots, 40)$; $G_{l}=$ fixed effect of lactation group $(l=1,2,3)$, where $1=$ full lactation of $305 \mathrm{~d}, 2=$ culled before $305 \mathrm{~d}$ of lactation, $3=$ lactation extended due to ongoing lactation; $b \times C I=$ regression on calving interval; $b_{1} \times p_{D H}$ $+b_{2} \times p_{D R}+b_{3} \times p_{D J}=$ regression on the proportion of DH $\left(p_{D H}\right), \mathrm{DR}\left(p_{D R}\right)$, and DJ $\left(p_{D J}\right)$ genes respectively; $b_{1 \backslash 2} \times$ het $_{D H \backslash D R}+b_{1 \backslash 3} \times$ het $_{D H \backslash D J}+b_{2 \backslash 3} \times$ het $_{D R \backslash D J}=$ regression on the degree of heterozygosity between $\mathrm{DH}$ and DR (het $\left.t_{D H \mid D R}\right), \mathrm{DH}$ and DJ (het $\left.t_{D H \mid D J}\right)$, and between DR and DJ (het $\left.t_{D R \mid D J}\right)$, respectively; $a_{m}=$ a random additive genetic effect of cow $m ; e_{i j k l m}=$ random residual.

Heterosis was estimated assuming a dominance model as explained by Sørensen et al. (2008) with dominance effects modeled as regressions on degree of heterozygosity between the 3 breeds expressed as:

$$
\text { het }_{i j}=P_{S i} \times P_{D j}+P_{S j} \times P_{D i},
$$

where $P$ is the breed proportion for sires $(S)$ and dams $(D)$ of breed ( $i$ and $j$ ).

The majority of the genes originate from DH $(56 \%)$ and DR (34\%), whereas DJ only contribute with $10 \%$ in the crossbred animals (Table 1). Phenotypic means showed that crossbred cows had higher MY $(7,828 \mathrm{~kg})$ than DJ $(5,915 \mathrm{~kg})$, and DR $(7,809)$ but lower MY than DH $(8,460)$. The PY for crossbred cows equaled those for DR and was higher than for DJ, but their PY was lower than for DH (Table 1). Fat yield was highest for DJ, followed by DH and crossbreds. Crossbred cows had the lowest SCS (11.41), and the lowest mastitis incidence (0.086), whereas Jerseys had the highest SCS (11.77).

Table 2 presents the effect of breed proportion for DR and DJ relative to a pure DH. There was no difference in PY between DH and DR. There was a significant $(P$
$<0.05)$ effect of breed in MY for DR and DJ, which yielded 461 and $2,259 \mathrm{~kg}$ milk less than DH. DJ had the same FY as DH whereas DR yielded $10.2 \mathrm{~kg}$ fat less than DH. DR had lower SCS than DH (-0.13), whereas SCS was higher for DJ (0.14). The effect of breed proportion for mastitis was insignificant for both DR and DJ (Table 2).

Heterosis for MY, PY, and FY was significant for all combinations of breeds (Table 3 ) and ranged between 3.1 to $6.8 \%$, which corresponds to previous findings by Lembeye et al. (2016) and Bryant et al. (2007). These figures also correspond well with heterosis estimates for MY, PY, and FY for crosses between Holstein and Jersey, Holstein and Ayrshire, and Ayrshire and Jersey presented in Lopez-Villalobos et al. (2000). As expected, heterosis for PY, MY, and FY was largest for $\mathrm{F}_{1}$-crosses involving $\mathrm{DJ}$, which corresponds to finding by Lopez-Villalobos et al. (2000). The higher heterosis obtained for crosses with DJ is because the genetic distance between DJ and the other breeds are larger than the genetic distance between DR and DH (B. Guldbrandtsen, Aarhus University, Tjele, Denmark, personal communication).

According to quantitative genetic theory, the expectation is that heterosis is largest for fitness traits and traits with low heritability (Falconer and Mackay, 1996). In our study, heterosis effects for SCS were only significant for crosses between DH and DR. Dechow et al. (2007) found a significant favorable heterosis effect for SCS using data from cows of crosses between Holstein and Brown Swiss. On the contrary, VanRaden and Sanders (2003) found a small unfavorable heterosis effect. The unfavorable effect on SCS was explained by the increased milk production seen for crossbreed cows, which may increase the stress on the udder. Our results indicate that heterosis for SCS exists but only for crosses between DH and DR. However, we had little information on crosses with DJ so it is likely that we did not have enough data to detect a significant heterosis effect, which was also supported by a higher SE for crosses between DH and DJ or DR and DJ compared with crosses between DH and DR. With respect to MAST, heterosis effects were not significant for any of the breed combinations. There are few previ- 
Madsen, P., and J. Jensen. 2013. A user's guide to DMU. A package for analyzing multivariate mixed models. Ver. 6, rel. 5.2. Accessed August 6, 2019. http://dmu.agrsci.dk/DMU/Doc/Current/dmuv6 guide.5.2.pdf.

Mäki-Tanila, A. 2007. An overview on quantitative and genomic tools for utilizing dominance genetic variation in improving animal production. Agric. Food Sci. 16:188-198. https://doi.org/10.2137/ 145960607782219337.

NAV (Nordic Cattle Genetic Evaluation). 2020. NAV routine genetic evaluation of dairy cattle - data and genetic models. Accessed April 16, 2020. https://www.nordicebv.info/wp-content/uploads/ 2020/01/NAV-routine-genetic-evaluation_including-saved-feed -26122019.pdf.

Prendiville, R., K. M. Pierce, and F. Buckley. 2010. A comparison between Holstein-Friesian and Jersey dairy cows and their F1 cross with regard to milk yield, somatic cell score, mastitis, and milking characteristics under grazing conditions. J. Dairy Sci. 93:27412750. https://doi.org/10.3168/jds.2009-2791.

SEGES. 2019. Racesammensætning for kalve af malkerace født 19852018. Accessed April 16, 2020. https://www.landbrugsinfo.dk/ Kvaeg/Avl/Avlsstatistik/Sider/Racesammensaetning-for-kalve-af -malkerace-foedt-1985-.aspx.

Sørensen, M. K., E. Norberg, J. Pedersen, and L. G. Christensen. 2008. Invited review: Crossbreeding in dairy cattle: A Danish perspec- tive. J. Dairy Sci. 91:4116-4128. https://doi.org/10.3168/jds.2008 $-1273$.

VanRaden, P. M., and A. H. Sanders. 2003. Economic merit of crossbred and purebred US dairy cattle. J. Dairy Sci. 86:1036-1044. https://doi.org/10.3168/jds.S0022-0302(03)73687-X.

de Vienne, D., and J. B. Fiévet. 2020. The pitfalls of heterosis coefficients. Plants 9:875. https://doi.org/10.3390/plants9070875.

Wiggans, G. R., and L. D. Van Vleck. 1979. Extending partial lactation milk and fat records with a function of last-sample production. J. Dairy Sci. 62:316-325. https://doi.org/10.3168/jds.S0022 -0302(79)83242-7.

\section{ORCIDS}

M. Kargo ๑ https://orcid.org/0000-0003-1981-2722

J. B. Clasen (๑ https://orcid.org/0000-0001-7988-5400

H. M. Nielsen ( ) https://orcid.org/0000-0002-8001-5629

K. Byskov @ https://orcid.org/0000-0003-1420-0313

E. Norberg ๑ https://orcid.org/0000-0002-9807-7473 